\title{
Use of child safety seats during transportation of newborns
}

\author{
Seon Hyuk Kim, MD, Sung Won Park, MD, PhD, Yeon Kyung Lee, MD, PhD, Sun Young Ko, MD, PhD, Son Moon Shin, MD, PhD \\ Department of Pediatrics, Cheil General Hospital and Women's Healthcare Center, Dankook University College of Medicine, Seoul, Korea
}

Purpose: Child safety seats (CSS) are critical for the protection of children, in case of motor vehicle accidents. Although the national legislation mandates that all newborns must be placed in an appropriately installed CSS during transportation, people often do not perceive the importance of CSS and do not use it as recommended. The purpose of this survey was to understand the use of CSS for the safe transport of newborns from hospital to home.

Methods: We interviewed parents of newborn infants, using a structured questionnaire, at the time of their discharge from Cheil General Hospital \& Women's Health Care Center, between May 2014 and July 2014.

Results: A total of 403 participants were interviewed. The rate of CSS use was only $14.9 \%$. Overall, $76.4 \%$ of the families interviewed were not aware about the recommendations on CSS use for newborns when travelling in a car. The provision of education on using CSS significantly influenced their rate of use. Parents who were educated about mounting the CSS in a car used it more as compared with others (25.7\% vs. $12.2 \%)(P=0.002)$. Furthermore, if parents had heard about the importance or necessity of CSS, they used it more than others did ( $19.5 \%$ vs. $10.6 \%, P=0.032)$.

Conclusion: Despite the legal regulation, most parents transport their newborn infants without a CSS while traveling from hospital to their home. The rate of CSS use was influenced by parental education and their knowledge about its necessity. Education programs for parents must be reinforced to increase the cSS use.

Key words: Child safety seats, Child restraint systems, Seat belts

\section{Introduction}

Injuries are the leading cause of child mortality and road traffic accidents are the major cause, accounting for approximately $41 \%$ of injury related child mortality. ${ }^{1)}$ Child safety seats (CSS) are critical for protecting children and help in preventing injury, thus reducing child mortality and morbidity in road traffic accidents. The National Highway Traffic Safety Administration Fatality Analysis Reporting System (http://www.nhtsa.gov/) reported that between 1988 and 1994, CSS reduced fatality risk by 71\% in passenger cars and 58\% in light trucks and vans for infants (aged $<1$ year), and by 54\% in passenger cars and 59\% in light trucks and vans for toddlers (aged 1-4 years). ${ }^{2)}$ Following this, the American Academy of Pediatrics issued a statement advising parents on how to select, install and place their child safely in a CSS, to prevent injuries in case of motor vehicle accidents. ${ }^{3)}$ For optimal protection, CSS use is recommended for all children including newborn babies. Rice and Anderson ${ }^{4)}$ found that CSS reduced the risk of fatality by $67 \%$ for children aged 0-3 years, with those aged $<1$ year having a reduced fatality risk by as much as $73 \%$ compared to unrestrained children. Hence, the use of CSS should begin right from the first ride that newborns take, when they are
Corresponding author: Son Moon Shin, MD, PhD Department of Pediatrics, Cheil General Hospital \& Women's Healthcare Center, Dankook University College of Medicine, 17 Seoae-ro 1-gil, Jung-gu, Seoul 04619, Korea

Tel: +82-2-2000-4714

Fax: +82-2-2000-7778

E-mail: smshinmd@hanmail.net

https://orcid.org/0000-0002-3743-3307

Received: 12 September, 2017

Revised: 8 November, 2017

Accepted: 9 November, 2017

Copyright $(\bigodot 2018$ by The Korean Pediatric Society

This is an open-access article distributed under the terms of the Creative Commons Attribution NonCommercial License (http://creativecommons.org/ licenses/by-nc/4.0// which permits unrestricted noncommercial use, distribution, and reproduction in any medium, provided the original work is properly cited. 
discharged from the hospital to their home.

In Korea, motor vehicle accidents are the leading cause of child mortality aged one to 15 years. According to the Road Traffic Act (RTA) in Korea, it is mandatory for the driver to fasten his seat belt and he has a duty to insist the fellow passenger to fasten the seat belt. If the fellow passenger is a child, the driver should ensure that the child wears a protect gear (car seat) and it is fastened with the seat belt. Despite regulation by the law, parents use CSS less frequently compared with other countries. ${ }^{5)}$ Although there is no data about CSS use by age, use of CSS in newborn babies is even lower than in infants or older children and they are often transported from hospital to home in their parent's or caregiver's arms in the car. The purpose of the survey was to understand how newborns are transported from hospital to their home after birth, and to understand the caregivers' knowledge about CSS use.

\section{Materials and methods}

We conducted interviews between May 1, 2014 and July 31, 2014 using structured interview sheets. Parents of newborn infants, discharged from the newborn nursery of Cheil General Hospital $\mathrm{Ct}$ Women's Health Care Center, were explained about this study and parents who provided their consent to participate, were enrolled. Parents of babies admitted to the neonatal intensive care unit were excluded. During the interview, the RTA law about CSS use and best practice guidelines were shared with the parents, and they were asked if they were aware of the law and guidelines.

The questionnaire consisted of 22 questions; 10 related to demographic data including age, sex, parity, delivery mode, educational background, household income, and relationship with the baby; 4 questions about CSS use, including plans for transporting the baby home, whether CSS had been bought and installed; and 8 questions on the parents' attitude and knowledge about CSS use. The questions related to CSS also included questions like, their source of information about CSS use, what they believe is the best way to transport a newborn in the car, whether they have been educated about CSS use and think they should use CSS while transporting their baby in the car.

Summary statistics for survey data were calculated. The relationship between the characteristics or education status of parents and CSS use was evaluated using the chi-square test, the Fisher exact test. All analyses were performed using IBM SPSS Statistics ver. 20.0 (IBM Co., Armonk, NY, USA) ( $P \leq 0.05$ defined statistical significance for all tests). The institutional review boards of Cheil General Hospital \& Women's Health Care Center approved this study (approval number: CGH-IRB-2014-19).

\section{Results}

During the study period, 1,347 parents of 1,402 newborn infants, including 42 twins were discharged from the hospital. A total of 403 participants were enrolled, after excluding 104 parents whose newborn infants were admitted to the neonatal intensive care unit and 840 parents who refused to join the study. We excluded data of 35 parents, who provided incomplete answers or contradictory inconsistent answers.

The mean maternal and paternal age was 34.2 \pm 3.7 years (range, 20-44 years) and 36.3 \pm 3.8 years (range, 25-47 years), respectively. Overall, $76.4 \%$ of the interviewed families were not aware about the recommendation that newborn infants must be restrained in CSS, when being transported in a car. The rate of CSS use was only $14.9 \%$.

With increasing parental age, there was better awareness of the importance of CSS which is the single most effective method for preventing serious or fatal injury in vehicle accident (maternal age, $P=0.028$; paternal age, $P=0.048$ ); however, there was no difference in the rate of CSS use.

First of all, we asked all interviewees $(n=368)$ about perception (include importance of CSS) and knowledge about CSS (include law, education experience about installation method). The higher maternal education level was related to the better perception of the importance of using CSS $(P=0.036)$ and knowledge of its correct installation (rear-facing only. place in back seat of vehicle) $(P<$ 0.001) (Table 1). Furthermore, between interviewees who were actually use car to back to home ( $n=338)$, if parents had heard about the importance or necessity for CSS use, they used CSS more frequently than others did ( $P=0.032$ ) (Table 2). Prior education on CSS use significantly influenced the rate of use; Parents who were educated about the installation method, used CSS more frequently than the others $(P=0.002)$. Twenty-nine point nine percent $(29.9 \%, \mathrm{n}=101)$ of parents had received education for installation method. The most common source of information was television (47.6\%). There was no significant difference in the use of CSS with parity $(P=0.583)$ and household income $(P=0.062)$.

The most common reason for parents and caregivers for not using CSS, was their perception that a newborn infant restrained in a CSS was at higher risk, than while being carried in a parent's or caregiver's arms, during transport in a car (36.1\%). Some parents even thought that carrying the baby in their arms would make it more comfortable and demonstrate their affection for the baby (7.5 \%). While some parents do not perceive the necessity of using CSS (25.5\%), others do not use it due to economic reasons (20.3\%).

\section{Discussion}

The significance of using CSS for prevention of injuries and 
Table 1. Association between characteristics of parents and usage of car safety seats

\begin{tabular}{|c|c|c|c|c|}
\hline \multirow{2}{*}{ Variable } & \multicolumn{2}{|c|}{ Perception of the importance of using CSS } & \multicolumn{2}{|c|}{ Knowledge about CSS correct installation } \\
\hline & Yes $(n=235)$ & No $(n=133)$ & Yes $(n=94)$ & No $(n=274)$ \\
\hline \multicolumn{5}{|l|}{ Maternal age (yr) } \\
\hline$\leq 29(\mathrm{n}=37)$ & $18(4.9)$ & $19(5.2)$ & $7(1.9)$ & $30(8.2)$ \\
\hline $30-39(n=296)$ & $194(52.7)$ & $102(27.7)$ & $80(21.7)$ & $216(58.7)$ \\
\hline$\geq 40(n=35)$ & $23(6.3)$ & $12(3.3)$ & $7(1.9)$ & $28(7.6)$ \\
\hline$P$ value & - & 0.028 & - & 0.890 \\
\hline \multicolumn{5}{|l|}{ Paternal age (yr) } \\
\hline$\leq 29(n=13)$ & $4(1.1)$ & $9(2.4)$ & $1(0.3)$ & $12(3.3)$ \\
\hline $30-39(n=274)$ & $179(48.6)$ & $95(25.8)$ & $82(22.3)$ & $192(52.2)$ \\
\hline$\geq 40(n=81)$ & $52(14.1)$ & $29(7.9)$ & $11(3.0)$ & $70(19.0)$ \\
\hline$P$ value & - & 0.048 & - & 0.061 \\
\hline \multicolumn{5}{|l|}{ Maternal education } \\
\hline High school graduated $(n=24)$ & $11(3.0)$ & $13(3.5)$ & $1(0.3)$ & $23(6.3)$ \\
\hline University or college graduated ( $n=287$ ) & $183(49.7)$ & $104(28.3)$ & $70(19.0)$ & $217(59.0)$ \\
\hline Graduate school graduated $(n=57)$ & $41(11.1)$ & $16(4.3)$ & $23(6.3)$ & $34(9.2)$ \\
\hline$P$ value & - & 0.036 & - & $<0.001$ \\
\hline \multicolumn{5}{|l|}{ Paternal education (n) } \\
\hline High school graduated $(n=25)$ & $10(2.7)$ & $15(4.1)$ & $3(0.8)$ & $22(6.0)$ \\
\hline University or college graduated $(n=274)$ & $178(48.4)$ & $96(26.1)$ & $73(19.8)$ & $201(54.6)$ \\
\hline Graduate school graduated $(n=69)$ & $39(10.6)$ & $30(8.2)$ & $18(4.9)$ & $51(13.9)$ \\
\hline$P$ value & - & 0.261 & - & 0.361 \\
\hline \multicolumn{5}{|l|}{ Household income (10 thousand KRW) } \\
\hline$<3,000(n=29)$ & $22(6.0)$ & $7(1.9)$ & $3(0.8)$ & $26(7.1)$ \\
\hline $3,000-6,000(n=148)$ & $88(23.9)$ & 60 (16.3) & $7(1.9)$ & $141(38.3)$ \\
\hline$>6,000(n=191)$ & $125(34.0)$ & $66(17.9)$ & $18(4.9)$ & $173(47.0)$ \\
\hline$P$ value & - & 0.939 & - & 0.106 \\
\hline
\end{tabular}

Values are presented as number (\%).

CSS, child safety seats; KRW, Korean won (the currency of South Korea).

deaths among infants and children cannot be overemphasized. Keeping parameters like vehicle characteristics, crash characteristics, and crash severity constant, CSS is associated with an estimated $80 \%$ reduction in the odds of injury, relative to a safety belt. ${ }^{6}$

A major hurdle in increasing the appropriate use of CSS is the lack of parents' knowledge about the importance and the method to use it. In this study, we investigated the parents' knowledge and practice of using CSS for their babies, during their first ride home from the newborn nursery in Korea.

In 1990 and 1999, the American Academy of Pediatrics (AAP) issued a policy statement titled, "Safe Transportation of Newborns Discharged from the Hospitals" recommending that all hospitals should set policies that mandate the discharge of every newborn in a CSS that is appropriate for the infants maturity and medical condition. It should also include a parent education component, regular review of educational materials, and periodic in-service education for the care giving staff., ${ }^{7,8}$

In Korea, the legal regulation for CSS use was specified in the RTA in 1990. Despite the RTA regulation, we found that most parents held their newborns in their arms while taking them home from the hospital, without using CSS. At times, parents do not follow the recommendation, either due to cultural reasons or because they have not been educated about CSS use.

The commonest reason for parents and caregivers not using CSS, was their perception that a newborn infant restrained in a CSS was at higher risk, than while being carried in a parent's or caregiver's arms, during transport in a car. Some parents even thought that carrying the baby in their arms would make it more comfortable, and demonstrate their affection for the baby

In brief, lack of knowledge and poor understanding about CSS use, seem to be the major barriers in the appropriate use of CSS for newborn infants. In this study, the rate of CSS use for a newborn baby was only $16 \%$; extensive public education is necessary to increase awareness of the effective and correct use of CSS for newborns. This is consistent with the 2011 AAP Policy statement. ${ }^{7)}$ In our study, parents with poorer academic qualifications were more 
Table 2. Comparison of characteristics between actual usage of car safety seats

\begin{tabular}{|c|c|c|c|}
\hline Variable & $\begin{array}{l}\text { Use CSS } \\
(n=55)\end{array}$ & $\begin{array}{l}\text { Not use CSS } \\
\quad(n=283)\end{array}$ & $P$ value \\
\hline \multicolumn{4}{|l|}{ Parity } \\
\hline $1(n=201)$ & $34(10.1)$ & $167(49.4)$ & 0.583 \\
\hline $2(n=122)$ & $20(5.9)$ & $102(30.2)$ & \\
\hline $3 \leq(n=15)$ & $1(0.3)$ & $14(4.1)$ & \\
\hline \multicolumn{4}{|l|}{ Sex (baby) } \\
\hline Male $(n=184)$ & $28(8.3)$ & $156(46.2)$ & 0.418 \\
\hline Female $(n=154)$ & $27(8.0)$ & $127(37.6)$ & \\
\hline \multicolumn{4}{|l|}{ Maternal age (yr) } \\
\hline$\leq 29(\mathrm{n}=37)$ & $8(2.4)$ & $26(7.7)$ & 0.566 \\
\hline $30-39(n=272)$ & $41(12.1)$ & $231(68.3)$ & \\
\hline$\geq 40(n=32)$ & $6(1.8)$ & $26(7.7)$ & \\
\hline \multicolumn{4}{|l|}{ Paternal age (yr) } \\
\hline$\leq 29(n=11)$ & $2(0.6)$ & $9(2.7)$ & 0.714 \\
\hline $30-39(n=258)$ & $44(13.0)$ & $214(63.3)$ & \\
\hline$\geq 40(n=69)$ & $9(2.7)$ & $60(17.8)$ & \\
\hline \multicolumn{4}{|l|}{ Maternal education } \\
\hline High school graduated $(n=19)$ & $0(0.0)$ & $19(5.6)$ & 0.046 \\
\hline University or college graduated ( $n=265$ ) & $42(12.4)$ & $223(66.0)$ & \\
\hline Graduate school graduated $(n=54)$ & $13(3.8)$ & $41(12.1)$ & \\
\hline \multicolumn{4}{|l|}{ Paternal education } \\
\hline High school graduated $(n=23)$ & $1(0.3)$ & $22(6.5)$ & 0.909 \\
\hline University or college graduated $(n=249)$ & $43(12.7)$ & $206(60.9)$ & \\
\hline Graduate school graduated $(n=66)$ & $11(3.3)$ & 55 (16.3) & \\
\hline \multicolumn{4}{|l|}{ Household income (10 thousand KRW) } \\
\hline$<3,000(\mathrm{n}=22)$ & $3(0.9)$ & $19(5.6)$ & 0.062 \\
\hline $3,000-6,000(n=139)$ & $22(6.5)$ & $117(34.6)$ & \\
\hline$>6,000(n=177)$ & $30(8.9)$ & $147(43.5)$ & \\
\hline \multicolumn{4}{|l|}{ Notice for necessity } \\
\hline Yes $(n=215)$ & $42(12.4)$ & $173(51.2)$ & 0.032 \\
\hline No $(n=123)$ & $13(3.8)$ & 110 (32.5) & \\
\hline \multicolumn{4}{|l|}{ Education for installation method } \\
\hline Yes $(n=101)$ & $26(7.7)$ & $75(22.2)$ & 0.002 \\
\hline No $(n=237)$ & $29(8.6)$ & $208(61.5)$ & \\
\hline
\end{tabular}

Values are presented as number (\%).

CSS, child safety seats; KRW, Korean won (the currency of South Korea).

likely to not use CSS for their newborn babies, which is similar to results from previous reports." These results highlight the need for education on the use of CSS, starting with the first ride home, especially among mothers who have not acquired a college degree, compared to mothers who possess a college degree.

In our study, 3.5\% parents planned to take their newborns home by taxi or other modes of public transportation. These babies were at immediate risk of unsafe transport in the absence of a CSS. A hospital based CSS service would be of help in such situations.

In addition, our study found no difference in CSS use among first-time mothers, compared to mothers who had children earlier, suggesting the need for CSS education regardless of maternal parity.

The limitations of this study include a small sample size drawn from one urban hospital in Seoul, South Korea. The survey-related data were subject to bias. The survey responses were clearly indicated as anonymous, but the responses may be significantly affected by bias such as the concept of social desirability. The participation rate in our study was $32.4 \%$. We were able to obtain demographic information about the population of mothers who did not participate, and found that they were not significantly different in terms of age, health insurance status and other factors. Our sample population was representative of the mothers delivering babies at this facility. Another limitation of our study is self-selection.

Also, in this study, the status of CSS possession was not taken into account while discussing the CSS education and installation correlation. It may be more likely that a person who has a CSS would have obtained education for installation method or have a higher recognition for the importance of CSS installation. Future studies will likely require consideration of such matter.

Our findings have several important implications. Based on this study, several recommendations can be made to help parents transport their newborn babies safely. Few newborn caregivers receive adequate education and training about CSS use, which results in lower usage. Comprehensive education regarding general child safety guidelines, focusing specifically on the importance of motor vehicle safety, from the baby's first ride home itself, should be undertaken. Training designed to improve CSS use should incorporate CSS training in birthing hospitals, as part of antenatal care and in the newborn nurseries before discharge from nursery room. If parents plan to take their newborns home in a taxi or any other public transportation, CSS rental programs, for example, rent a CSS for use in a taxi, could be a good option. As reported by Eventov-Friedman et al. ${ }^{10)}$ through the 'safe taxi' program in Israel, CSS rented for transport of newborn babies in a taxi, was able to increase child passenger safety awareness and safety practices in these populations. Using safe taxi service to transport newborn babies home from hospital, will reduce injuries and save children's lives. ${ }^{10)}$ We suggest that healthcare providers should identify parents of newborn infants who do not plan to use CSS. These high-risk populations should be provided with appropriate child passenger safety interventions, including education and CSS rental programs.

In conclusion, despite the legal regulation that newborns must be transported in CSS, we found that many parents do not use and do not perceive the need for using CSS in Korea. Public education regarding the need and the correct technique for installing the CSS can increase its use and improve safety of infants during motor vehicle transport. We suggest that all medical facilities should prepare their policies to educate parents about CSS and implement its use especially at the time of hospital discharge. 


\section{Conflicts of interest}

No potential conflict of interest relevant to this article was reported.

\section{References}

1. UNICEF, International Child Development Centre. A league table of child deaths by injury in rich nations. Innocenti Report Card No 2. February 2001. UNICEF Innocenti Research Centre. Florence (Italy): UNICEF, 2001.

2. National Highway Traffic Safety Administration. Revised estimates of child restraint effectiveness. Washington, DC: National Highway Traffic Safety Administration, 1996

3. American Academy of Pediatrics, Committee on Injury and Poison Prevention. Selecting and using the most appropriate car safety seats for growing children: guidelines for counseling parents. Pediatrics 2002;109:550-3.
4. Rice TM, Anderson CL. The effectiveness of child restraint systems for children aged 3 years or younger during motor vehicle collisions: 1996 to 2005. Am J Public Health 2009;99:252-7.

5. Ministry of Land, Infrastructure and Transport [Internet]. Sejong (Korea): Ministry of Land, Infrastructure and Transport, 2012 [cited 2015 Jun 13]. Available from: http://www.molit.go.kr/portal.do.

6. Zaloshnja E, Miller TR, Hendrie D. Effectiveness of child safety seats vs safety belts for children aged 2 to 3 years. Arch Pediatr Adolesc Med 2007;161:65-8.

7. American Academy of Pediatrics, Committee on Injury and Poison Prevention. Safe transportation of newborns at hospital discharge. Pediatrics 1990;86:788-93.

8. Bull M, Agran P, Laraque D, Pollack SH, Smith GA, Spivak HR, et al. American Academy of Pediatrics. Committee on Injury and Poison Prevention. Safe transportation of newborns at hospital discharge. Pediatrics 1999;104(4 Pt 1):986-7.

9. Eby DW, Kostyniuk LP. A statewide analysis of child safety seat use and misuse in Michigan. Accid Anal Prev 1999;31:555-66.

10. Eventov-Friedman S, Bar-Oz B, Zisk-Rony RY. Using a safe taxi service to transport newborn babies home from hospital. Acta Paediatr 2014;103:57-61. 